Ambiente \& Água - An Interdisciplinary Journal of Applied Science
ISSN 1980-993X - doi:10.4136/1980-993X
www.ambi-agua.net
E-mail: ambi.agua@gmail.com

\title{
Heterogeneidade espacial e temporal de variáveis limnológicas no reservatório de Itupararanga associadas com o uso do solo na Bacia do Alto Sorocaba-SP
}

\author{
doi:10.4136/ambi-agua.1715
}

Received: 20 Jul. 2015; Accepted: 18 Sep. 2015

\section{Daniele Frascareli ${ }^{1 *}$; Frederico Guilherme de Souza Beghelli ${ }^{2}$; Sheila Cardoso da Silva ${ }^{2}$; Viviane Moschini Carlos ${ }^{1}$}

\author{
Universidade Estadual paulista "Júlio de Mesquita Filho" (UNESP), Sorocaba, SP, Brasil \\ ${ }^{1}$ Departamento de Engenharia Ambiental \\ ${ }^{2}$ Programa de Pós-Graduação em Ciências Ambientais \\ *Autor correspondente: e-mail: daniele.frascareli@posgrad.sorocaba.unesp.br, \\ fred_sb@hotmail.com, sheilacardoso@usp.br, viviane@sorocaba.unesp.br
}

\section{RESUMO}

Dentre as diversas atividades desenvolvidas no entorno de corpos de água, a poluição por agroquímicos e o lançamento de efluentes acarretam a carga excessiva de nutrientes que contribuem para o processo de eutrofização artificial e degradação destes ecossistemas. Neste contexto, os objetivos deste trabalho foram: determinar a heterogeneidade sazonal e espacial nas águas superficiais do reservatório Itupararanga e verificar a influência dos usos do entorno sobre a qualidade da água do reservatório localizado na cidade de Ibiúna, São Paulo, Brasil. Analisou-se o Índice de Estado Trófico (IET) e variáveis limnológicas em duas estações distintas - período seco e chuvoso de 2013. Os dados foram comparados com mapa de usos do solo e com parâmetros estabelecidos pela resolução CONAMA n ${ }^{\circ} 357$ de 2005. Os resultados demostraram que o fósforo total não esteve em conformidade com as especificações CONAMA. O reservatório apresentou heterogeneidade sazonal e espacial em relação ao IET e às variáveis limnológicas. Por meio da análise de agrupamento com os dados de qualidade de água e uso e ocupação dos solos foi comprovada a heterogeneidade espacial. A análise de agrupamento indicou que a cobertura florestal é um importante fator para a contenção da entrada de sólidos em suspensão. Indicou também que o uso agrícola é a principal fonte de nitrogênio para o meio enquanto que os rios formadores contribuem, principalmente com cargas de fósforo. Assim, por se tratar de uma área de importância social e econômica, medidas de preservação devem ser tomadas a fim de mitigar os avanços das atividades potencialmente impactantes.

Palavras-chave: eutrofização, heterogeneidade, qualidade de água.

\section{Spatial and seasonal heterogeneity of limnological variables in Itupararanga reservoir associated with the land use in the Bacia do Alto Sorocaba-SP}

\author{
ABSTRACT \\ Among the human activities around waterbodies, pollution by runoff of agrochemicals
}


and sewage discharges into waterbodies can cause nutrient loading, which contributes to the eutrophication process and degradation of these ecosystems. This work aimed to determine spatial and seasonal heterogeneity in surface waters of the Itupararanga Reservoir and analyzed the influence of land use on the reservoir water quality. The reservoir is used for water public supply and is located in Ibiúna City, São Paulo, Brazil. Trophic State Index (TSI) and limnological variables were analyzed in both the wet and dry seasons in 2013. Data were compared with land use maps and with Brazilian environmental legislation - CONAMA ${ }^{\circ}$ 357/2005. The results indicated that total phosphorus was not in compliance with the CONAMA standard. The reservoir showed spatial and seasonal heterogeneity for TSI and also for limnological variables. Spatial heterogeneity was demonstrated using cluster analysis of water quality and land use data. The cluster analysis indicated that forest cover is an important factor in preventing solids from entering into the system. It also indicated that agriculture practices around the Itupararanga Reservoir are the main sources of nitrogen, whereas tributaries are responsible for the major phosphorus inputs. Since the Itupararanga Reservoir is socially and economically important to the region, conservation and preservation measures are recommended in order to mitigate harmful activities to the aquatic environment.

Keywords: eutrophication, heterogeneity, water quality.

\section{INTRODUÇÃO}

Algumas práticas de usos do solo podem contribuir para a degradação dos ecossistemas. Estas práticas estão associadas principalmente à demanda por produção de alimentos agrícolas, à pecuária e à urbanização de áreas sem infraestrutura básica, como o recolhimento e tratamento de resíduos sólidos e líquidos, energia, entre outros. Quando essas atividades são desenvolvidas próximo a ecossistemas aquáticos, podem ter efeito negativo direto na qualidade da água e assim, causar crises na oferta e demanda hídrica (Tundisi, 2008).

A depreciação da qualidade da água em reservatórios essencialmente utilizados para o abastecimento público pode ter origens pontuais, como é o caso do despejo de efluentes domésticos e industriais, ou difusas como é o caso dos resíduos da agricultura (fertilizantes, herbicidas, etc.). Essas atividades desenvolvidas no entorno dos reservatórios podem comprometer os seus usos múltiplos, como já registrado por diversos autores (Cunha et al., 2010; Buzelli e Cunha-Santino, 2013; Santos et al., 2013; Cardoso-Silva et al., 2014).

Desta forma, a eutrofização tem gerado grandes prejuízos e tem direcionado a atenção dos pesquisadores a esses ecossistemas aquáticos (Moschini-Carlos et al., 2010; Taniwaki et al., 2011; 2013; Cunha et al., 2013a; Pedrazzi et al., 2013; Beghelli et al., 2015). A eutrofização artificial ocorre quando há disponível uma quantidade elevada de nutrientes no ambiente aquático, especialmente fósforo e nitrogênio (Camargo et al., 2003). Esses nutrientes quando lançados na água contribuem para o aumento da produtividade primária do sistema, resultando em um acúmulo de matéria orgânica e redução da penetração de luz (Azevedo e Feitosa, 2008), ocasionando a morte dos organismos mais sensíveis (Thomaz, 2008).

Para determinar o grau de eutrofização de um ecossistema aquático Carlson (1977) propôs índice de estado trófico (IET) para ambientes temperados. No Brasil, esse índice foi modificado e adaptado para ambientes tropicais e subtropicais por Toledo Jr. et al. (1983), Salas e Martino (1991) e, mais recentemente por Lamparelli (2004). Atualmente, foi proposto uma atualização do IET por Cunha et al. (2013b) para reservatório em ambientes tropicais e subtropicais. Estes últimos índices permitem classificar os ecossistemas aquáticos em diferentes graus de trofia, desde ultraoligotrófico categoria com menores concentrações de nutrientes até o estado de maior trofia, hipereutrófico. 
O reservatório de Itupararanga abastece aproximadamente um milhão de pessoas (Conceição et al., 2015) e está inserido em uma região de importância social e econômica. Estudos desenvolvidos no reservatório registraram heterogeneidade ao longo do espaço (Taniwaki et al., 2011; Pedrazzi et al., 2013) e do tempo (Taniwaki et al., 2013) em relação à eutrofização. Por essas razões, são necessários estudos ambientais que auxiliem no aperfeiçoamento da gestão dos recursos hídricos com o intuito de minimizar os impactos a esse ecossistema e assim evitar as perdas econômicas na recuperação do mesmo. Assim, o objetivo deste trabalho foi identificar as porções do reservatório Itupararanga mais afetadas pelas atividades do entorno, por meio de análise de variáveis físicas, químicas e biológicas e do grau de trofia do reservatório e comparação com um mapa de usos do solo e com a Resolução vigente CONAMA n³57/2005. Esta pesquisa poderá ser utilizada como subsídio para a criação e revisão de legislações que estimulem a melhoria contínua do recurso hídrico.

\section{MATERIAL E MÉTODOS}

\section{1. Área de estudo}

O reservatório de Itupararanga está localizado no alto do curso do Rio Sorocaba, maior afluente do rio Tietê na margem esquerda. O reservatório pertence a bacia do Alto Sorocaba, uma das sub-bacias que compõem a Bacia do Sorocaba Médio Tietê. A represa foi criada em 1912 e é formada pelos rios Sorocabaçu, Sorocamirim e Una. Possui a área da bacia de drenagem com $929 \mathrm{~km}^{2}$ que abrange os municípios de Alumínio, Cotia, Ibiúna, Mairinque, Piedade, São Roque, Vargem grande Paulista e Votorantim, onde está situada a barragem (Figura 1) (Taniwaki et al., 2013). A represa possui área de $29,9 \mathrm{~km}^{2}$, profundidade média de $7,8 \mathrm{~m}$ e tempo de residência médio anual de 250 dias (Giron, 2013). Possui vazão média afluente de $12,70 \mathrm{~m}^{3} \mathrm{~s}^{-1}$ e defluente de $12,68 \mathrm{~m}^{3} \mathrm{~s}^{-1}$ com fluxo máximo de $39,12 \mathrm{~m}^{3} \mathrm{~s}^{-1}$. A pluviosidade anual média da bacia é de $1.492,7 \mathrm{~mm}$, o clima Cwb de acordo com a classificação Köppen com verão chuvoso e estiagem no inverno (Conceição et al., 2015; Salles et al., 2008).

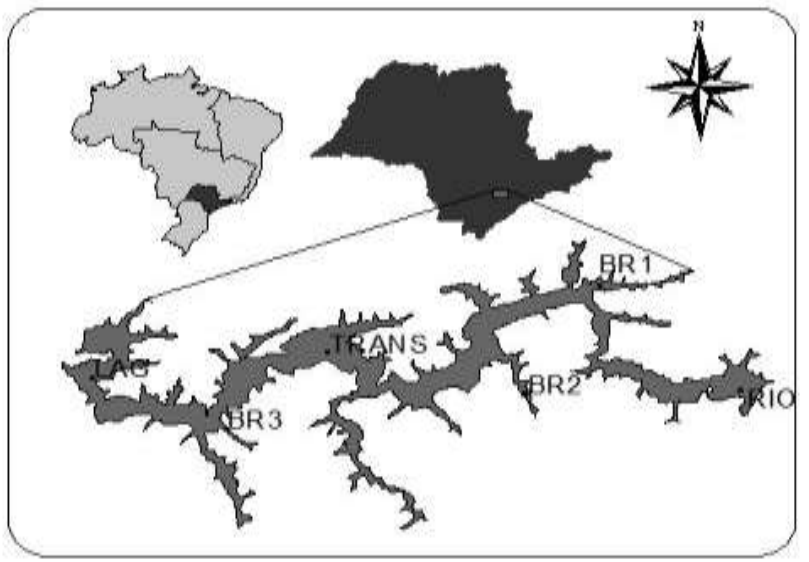

Figura 1. Localização reservatório de Itupararanga, São Paulo, Brasil e também dos pontos de coleta.

Em 1998, foi criada a Lei Estadual $\mathrm{n}^{\circ} 10.100$ que definiu a área de entorno do reservatório de Itupararanga como área de proteção ambiental (APA). Pela Lei Estadual $\mathrm{n}^{\circ}$ 11.579/2003, a APA foi regulamentada contendo todos os municípios que constituem a região do entorno, com o intuito de proteger os reservatórios e sua biodiversidade (Beu et al., 2011). Taniwaki et al. (2013) em uma análise dos usos do solo, determinaram que a área de entorno do reservatório possuía 3,4\% de solo exposto, 2,7\% ocupação urbana e 22,8\% agricultura, os 
autores registraram que essas atividades são negativamente impactantes para a qualidade da água e comprometem os usos múltiplos que o reservatório propicia a sociedade.

\subsection{Métodos}

Foram coletadas amostras de água superficial em seis pontos do reservatório de Itupararanga (Figura 1), em dois períodos do ano, abril caracterizando o período chuvoso e setembro de 2013 o período seco, afim de verificar sazonalidade. Nesses pontos foram tomadas coordenadas em Sistema de Posicionamento Global (GPS) (Lat Long). Sendo a localização dos pontos RIO: $23^{\circ} 37^{\prime} 17.03^{\prime \prime S}$ e $47^{\circ} 13^{\prime} 55.01^{\prime \prime O}$; BR1: $23^{\circ} 35^{\prime} 43.07^{\prime \prime S}$ e $47^{\circ} 16^{\prime} 0.98 " \mathrm{O}$; BR2: $23^{\circ} 37^{\prime} 35.14^{\prime \prime S}$ e $47^{\circ} 17^{\prime} 4.97^{\prime \prime O}$; TRANS: $23^{\circ} 37^{\prime} 1.42^{\prime \prime S}$ e $47^{\circ} 20^{\prime} 18.94^{\prime \prime O}$;

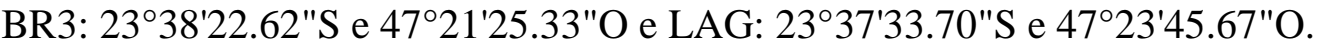

Foram determinadas in situ na água superficial das seguintes variáveis: temperatura (Temp), pH e condutividade elétrica da água (Cond) com utilização de uma sonda multiparâmetros YSI 63. Para a determinação da concentração de oxigênio dissolvido (OD) foi utilizado o método proposto por Winkler (1888) e modificado por Pomeroy e Kirshmam (1945). As concentrações de fósforo (PT) e nitrogênio totais (NT) foram determinadas por meio de leitura no espectrofotômetro Hach ${ }^{\circledR} 390080$ seguindo as metodologias CR 3900 e 10071 respectivamente. A determinação da clorofila-a $(\mathrm{Cl}-\mathrm{a})$ foi realizada segundo o método determinado por Wetzel e Likens (2000). Foi utilizada acetona 90\% como solvente na extração dos pigmentos fotossintéticos e os teores estimados segundo equação estabelecida por Lorenzen (1967) e as absorbâncias lidas em espectrofotômetro Micronal AJX-1900. Os sólidos totais (ST), sólidos dissolvidos (SD) e sólidos suspensos (SPS) foram determinados segundo Wetzel e Likens (2000) pelo método gravimétrico. Para os ST uma alíquota de 200 $\mathrm{ml}$ da água bruta foi seca em béquer previamente pesado à $105^{\circ} \mathrm{C}$ na estufa de aeração e, o peso pós estufa registrado. Para material em suspensão (SPS) foram empregados filtros Whatman GF/C $47 \mathrm{~mm} \varnothing$.

A análise de componentes principais (ACP) foi realizada de forma a se considerar a variação sazonal. Com o objetivo de se verificar o agrupamento das variáveis e sua relação com os usos do solo, foi efetuada também uma análise de cluster (UPGMA, distância de Gower) com análise de bootstrap com 100 reamostragens. Esta última análise, partiu de uma matriz padronizada em escore $\mathrm{z}$ por estação do ano de forma a se retirar a variabilidade sazonal da análise e incluiu as proporções dos diferentes usos do solo considerados por trecho. As análises estatísticas foram desenvolvidas com o software PAST 3.0 (Hammer et al., 2001).

Foi empregado o IET de Carlson (1977) modificado por Lamparelli (2004) para ambientes tropicais e subtropicais, utilizando-se os dados de PT e Cl-a. Em reservatórios o cálculo do IET é feito a partir dos valores de fósforo e clorofila-a utilizando a seguinte formula: IET $(\mathrm{PT})=10 *(6-(1,77-0,42 *(\ln \mathrm{PT}) / \ln 2))$; IET $(\mathrm{Cl}-\mathrm{a})=10 *(6-((0,92-0,34 *(\ln \mathrm{Cl}-$ a))/ln 2)) onde o fósforo total (PT) e a clorofila-a (Cl-a) são expressos em $\mu \mathrm{g} / \mathrm{L}$.

Os dados das variáveis físicas, química e biológicas foram comparados aos limites estabelecidos pela legislação vigente para corpos hídricos classe 2. O reservatório de Itupararanga está incluído na classe 2 , uma vez que segundo o artigo 42 da Resolução CONAMA n' 357/2005: "enquanto não aprovados os respectivos enquadramentos, as águas doces serão consideradas como classe 2".

Para a elaboração do mapa de usos do solo foi utilizado uma metodologia por interpretação visual baseada na utilização de imagens TM do satélite Landsat 5 (ano de 2013) em que foram vetorizadas as classes de uso ocorrentes na área com o auxílio do aplicativo AutoCad® versão 2014. Foi realizada uma avaliação in situ, para observação da distribuição dos usos na área de estudo. Posteriormente, delimitou-se uma distância de 500 metros de distância dos corpos hídricos, considerando que esta faixa englobava todos os usos e ocupações existentes no reservatório. Com o objetivo de analisar a influência das atividades 
do entorno nos pontos amostrais, três regiões distintas foram determinadas a priori: entrada, transição e barragem.

Para determinação da porcentagem da contribuição das cidades no lançamento de esgoto no reservatório de Itupararanga, foram utilizados dados do número da população total (IBGE, 2010) e do número de habitantes beneficiados com esgotamento sanitário (SNIS, 2013).

\section{RESULTADOS E DISCUSSÃO}

Foi possível determinar a heterogeneidade temporal usando Análise de Componentes Principais (ACP, Figura 2) que, claramente, separa os pontos do período seco e chuvoso agrupando em dois grandes conjuntos. O eixo 1, que explica $48 \%$ das variações, determinou que as estações se distinguem em relação aos SD $(0,89)$, Cl-a $(0,70)$, PT $(0,95)$, Cond $(-0,79)$ e OD $(-0,85)$. A ACP corroborou a informação de que no período chuvoso, com o aumento do escoamento superficial na bacia observa-se em geral maiores concentrações de sólidos na água (Lucas et al., 2010; Bucci e Oliveira, 2014) e nutrientes. A maior disponibilidade de nutrientes favorece consequentemente o aumento da produtividade primária (Khan et al., 2014), medida indiretamente pela concentração de Cl-a. A redução de OD observada no período chuvoso pode ser explicada pela decomposição da matéria orgânica (Melo et al., 2005), respiração de organismos aquáticos e oxidação de íons metálicos (Esteves, 2011).

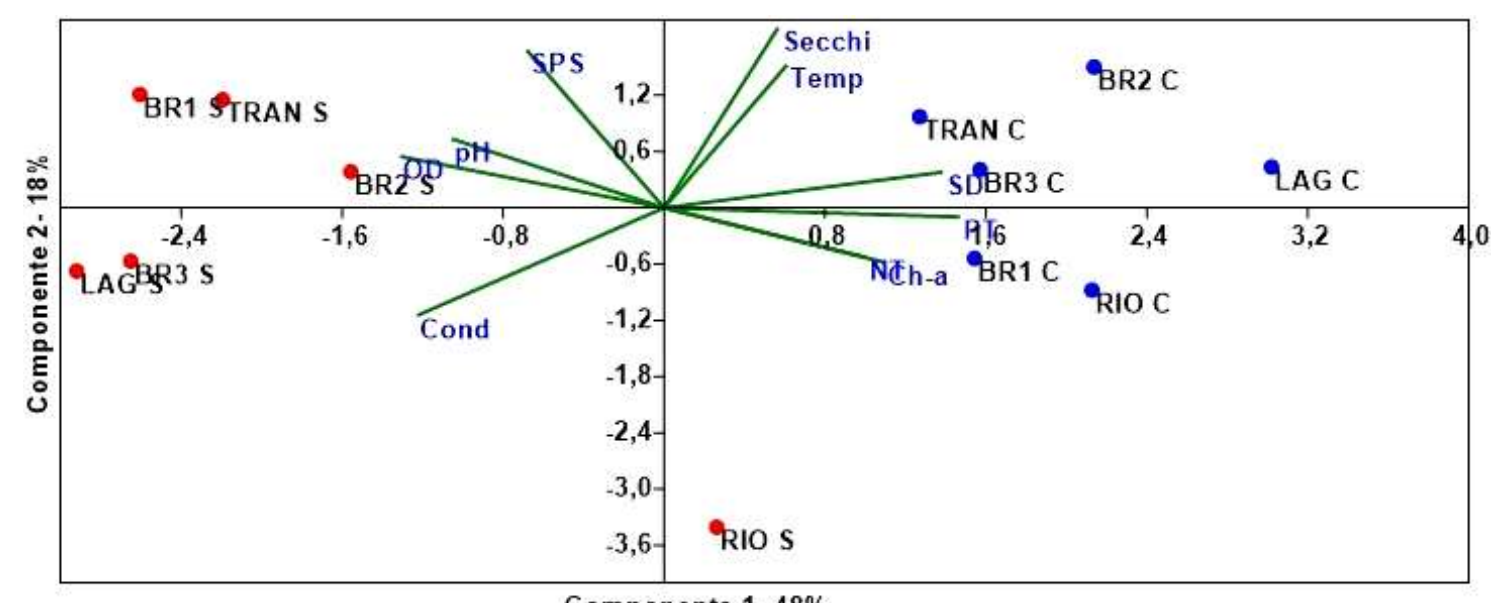

Figura 2. Análise de Componentes Principais (ACP) com dados padronizados da média total do período amostrado.

No período de seca, foi possível verificar altos valores de condutividade, isso se deve a redução da precipitação e o aumento da evaporação do corpo de água e, consequentemente, aumento da concentração de sais na água (Lobato et al., 2008; Lemos et al., 2010). Os teores mais elevados de OD neste período podem estar associados ao processo de eutrofização que foi menor no período seco.

\section{1. Índice de estado trófico (IET)}

Foi possível observar heterogeneidade sazonal em relação ao grau de trofia no reservatório de Itupararanga. De acordo com os cálculos do IET, os pontos do reservatório tiveram classificação no período chuvoso como hipereutrófico para o PT e uma variação hipereutrófica (RIO) à eutrófica (LAG) para a Cl-a. No período seco, o IET para o PT foi hipereutrófico e para a Cl-a variou de mesotrófico (LAG) à hipereutrófico (RIO) (Figura 3). Foi possível verificar também heterogeneidade horizontal no grau de trofia do reservatório no sentido montante-jusante, tendendo a valores menores em direção à barragem, variando no 
período chuvoso entre hipereutrófico à eutrófico e no período seco, supereutrófico à mesotrófico, assim como observado por Taniwaki et al. (2011).

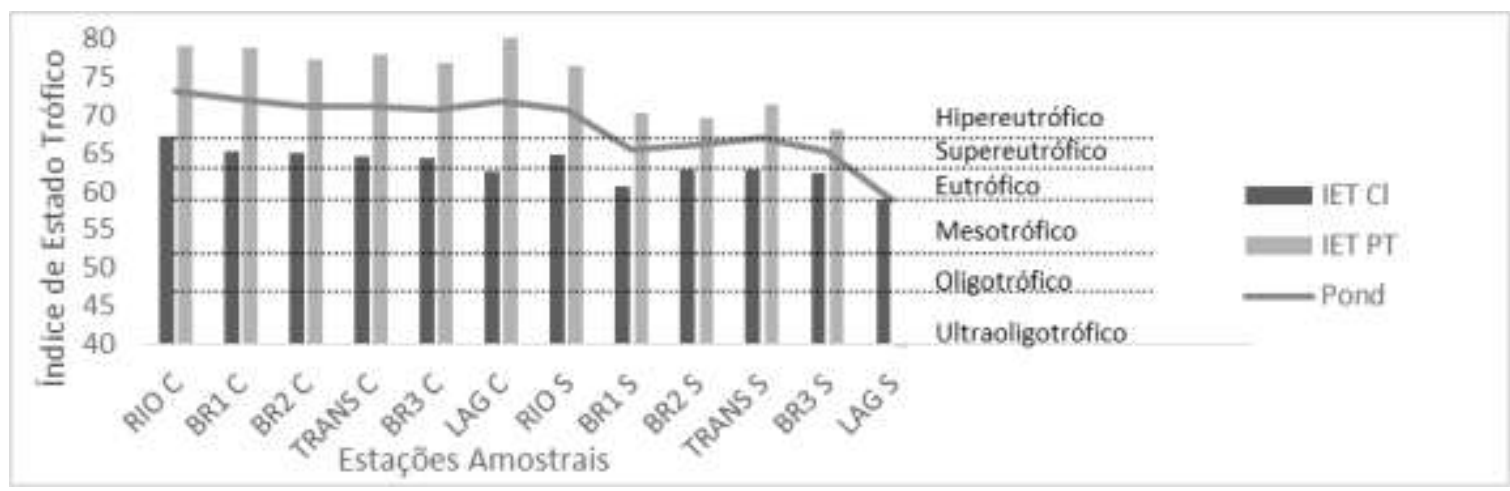

Figura 3. Valores dos cálculos do IET proposto por Carlson (1977) modificado por Lamparelli (2004) para o período chuvoso (C) e seco (S). Onde mesotrófico varia entre $52 \leq$ IET $\leq 59$, eutrófico - 59 $\leq$ IET $\leq 63$, supereutrófico- $63<$ IET $\leq 67$ e hipereutrófico $-67<$ IET. Pond representa a ponderação ou média dos resultados de IET (PT) e IET (Cl-a).

Com a comparação feita entre os IET (PT) e IET (Cl-a), observaram-se divergências entre as classificações, de forma que as classificações por PT tenderam a indicar um estado de maior eutrofização do que as de $\mathrm{Cl}$-a. Diante disso podem existir outros fatores que limitem a produtividade primária, como é o caso do nitrogênio. No presente estudo, o reservatório de Itupararanga apresentou no cálculo da razão $\mathrm{N}$ : $\mathrm{P}$ valores menores que 10 , indicando limitação por nitrogênio (Vidal e Capelo Neto, 2014).

A análise da conformidade com a legislação vigente determinou que somente as

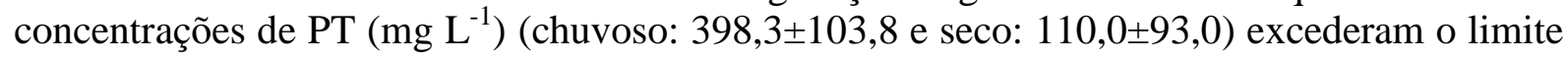
sugerido pela resolução (Tabela 1).

Tabela 1. Síntese das variáveis analisadas e limites estabelecidos na resolução CONAMA n $357 / 2005$.

\begin{tabular}{lccccc}
\hline \multicolumn{1}{c}{$\begin{array}{c}\text { Estações } \\
\text { Amostrais }\end{array}$} & $\begin{array}{c}\text { Amplitude } \\
\text { Chuvoso }\end{array}$ & Média & Amplitude Seco & Média & CONAMA 357/2005 \\
\hline Temp $\left({ }^{\circ} \mathrm{C}\right)$ & $22,6-20,6$ & $22,1 \pm 0,8$ & Seco & $21,4 \pm 0,7$ & \\
Cond $(\mu \mathrm{S})$ & $62-53$ & $58,5 \pm 3,6$ & $22,3-20,7$ & $74,0 \pm 3,3$ & \\
pH & $8,16-7,71$ & $7,9 \pm 0,2$ & $79-70$ & $8,2 \pm 0,3$ & Entre 6 e 9 \\
OD $\left(\mathrm{mg} \mathrm{L}^{-1}\right)$ & $7,71-6,74$ & $7,0 \pm 0,3$ & $8,6-7,8$ & $7,8 \pm 0,7$ & $>5 \mathrm{mg} \mathrm{L}^{-1}$ \\
STD $\left(\mathrm{mg} \mathrm{L}^{-1}\right)$ & $100,4-61,7$ & $86,9 \pm 16,4$ & $8,44-6,53$ & $38,5 \pm 5,0$ & $500,0 \mathrm{mg} \mathrm{L}^{-1}$ \\
SPS $\left(\mathrm{mg} \mathrm{L}^{-1}\right)$ & $4,3-2,3$ & $3,6 \pm 1,0$ & $47,1-34,0$ & $4,4 \pm 2,1$ & \\
Secchi & $1,62-1,17$ & $1,4 \pm 0,2$ & $6,6-0,9$ & $1,2 \pm 0,2$ & \\
Cl-a $\left(\mu \mathrm{g} \mathrm{L}^{-1}\right)$ & $28,8-11,3$ & $18,3 \pm 5,8$ & $1,43-1,01$ & $10,5 \pm 4,1$ & $<30.0$ \\
PT $\left(\mathrm{mg} \mathrm{L}^{-1}\right)$ & $585,0-300,0$ & $398,3 \pm 103,8$ & $17,0-5,1$ & $110,0 \pm 93,0$ & $<0,030^{*} \mathrm{e}^{-1}<0,050^{* *}$ \\
NT $\left(\mathrm{mg} \mathrm{L}^{-1}\right)$ & $1350,0-50,0$ & $608,3 \pm 442,1$ & $280,0-0,0$ & $216,7 \pm 256,3$ & $<1,27^{\alpha} \mathrm{e}<2,18^{\alpha \alpha}$ \\
\hline
\end{tabular}

*Para ambientes lênticos; **Para ambientes intermediários; ${ }^{\alpha}$ para ambientes lênticos; ${ }^{\alpha \alpha}$ Para ambientes lóticos.

A Figura 4 apresenta o mapa de usos e ocupação do solo gerado. Foi possível determinar 
as regiões e seus usos preponderantes, bem como os valores de uso na Tabela 2. A entrada do reservatório apresenta predominância de remanescente florestal que tende a diminuir em direção à barragem. Na direção da barragem as atividades antrópicas começam a atuar com maior intensidade, como: agricultura, pasto e atividade urbana.

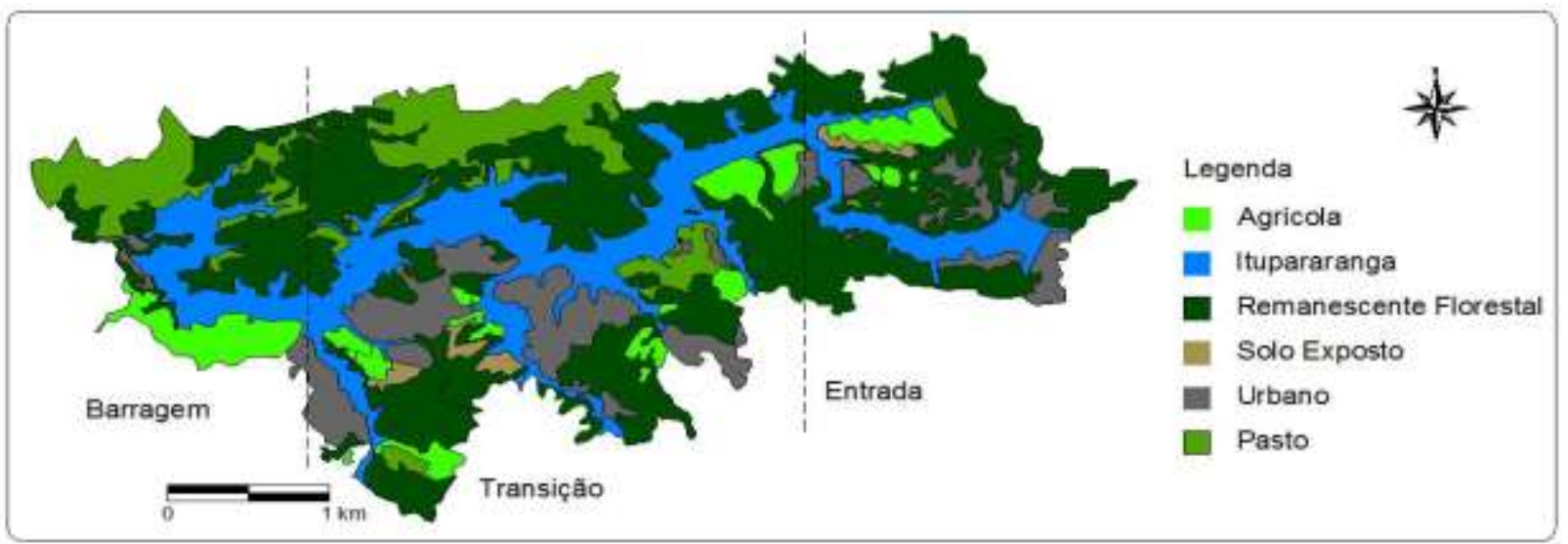

Figura 4. Mapa de usos do solo do entorno do reservatório de Itupararanga.

Tabela 2. Análise quantitativa (\%) dos usos e ocupação do solo por região do reservatório de Itupararanga.

\begin{tabular}{cccccc}
\hline & $\begin{array}{c}\text { Solo } \\
\text { exposto }\end{array}$ & Remanescente & Agricultura & Pasto & Urbano \\
\hline Barragem & N/A & 47.2 & 16.3 & 30.6 & 5.9 \\
Transição & 2.1 & 52.2 & 8.6 & 15.2 & 21.9 \\
Entrada & N/A & 77.6 & 7.2 & N/A & 15.2 \\
\hline
\end{tabular}

A análise cluster (Figura 5) indicou a região da entrada do reservatório como aquela que apresentou maiores valores para $\mathrm{Cl}$-a e PT, sendo, portanto, o trecho com maior grau de eutrofização. Considerando-se a importância da presença de vegetação natural nas margens de corpos de água e sua reconhecida atuação na retenção de poluentes e sedimentos do entorno (Naiman e Décamps, 1997) bem como o elevado estado trófico em que o reservatório se encontra, sugere-se que a eutrofização observada neste trecho é resultado da entrada excessiva de nutrientes nos trechos a montante do reservatório. Neste sentido, estes resultados corroboram com outros trabalhos que registraram a falta de saneamento e despejo de efluentes nos rios formadores (Sardinha et al., 2008; Salles et al., 2008; Pedrazzi et al., 2014) do reservatório Itupararanga. A falta de saneamento principalmente das cidades de Ibiúna, Vargem Grande Paulista e Cotia que lançam 92, 51 e 72\% (SNIS, 2013; IBGE, 2010), respectivamente, do esgoto gerado nos rios formadores do reservatório e assim, contribui para o aumento da trofia do mesmo.

As atividades agrícolas, na zona de transição, contribuíram para a entrada de NT no sistema, que é um elemento bastante móvel devido à baixa carga residual e facilmente lixiviado aos corpos de água superficiais (Capoane et al., 2014). A relação entre o uso urbano e atividades agropecuárias com as maiores proporções de material particulado dissolvido evidenciaram a importância da cobertura do solo para a retenção de partículas conforme supramencionado. 


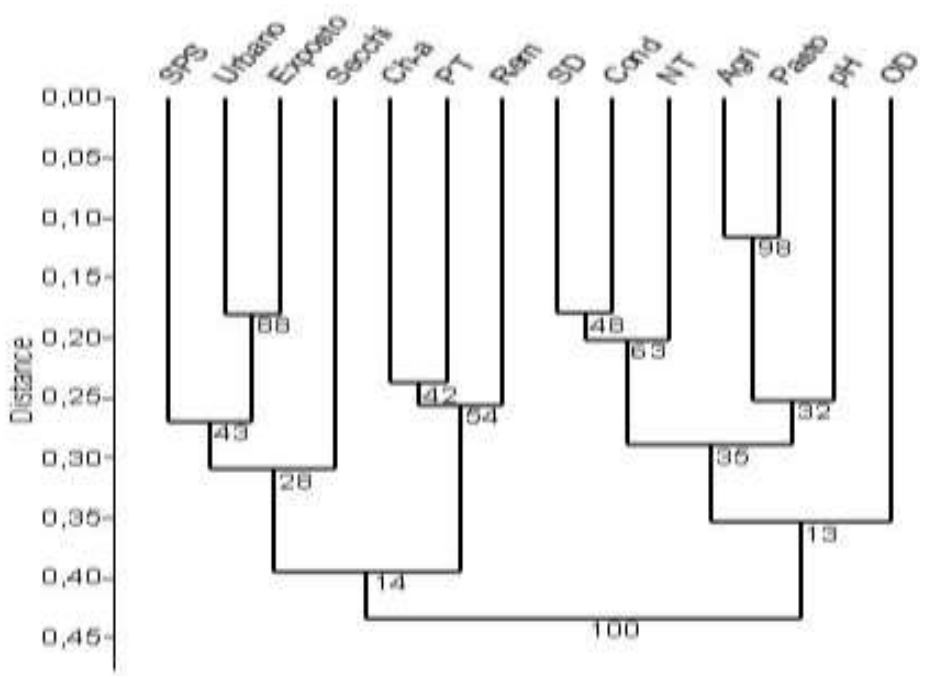

Figura 5. Cluster com os dados padronizados por escores z para cada estação amostral incluindo a proporção dos usos de solo de cada trecho considerado. Análise realizada pelo método cluster (UPGMA, distância de Gower) bootstrap com 100 reamostragens.

Esses fatores contribuem para a entrada de íons, poluentes na água (Franco e Hernandez, 2009) e também, na alteração das variáveis condutividade e pH, assim, no presente estudo essas as variáveis NT, condutividade e $\mathrm{pH}$ indicam a influência das atividades agrícolas sobre a qualidade da água enquanto que os usos urbano e de solo exposto demonstram o efeito negativo da remoção da cobertura vegetal sobre o reservatório de Itupararanga.

\section{CONCLUSÕES}

Conclui-se que o reservatório de Itupararanga apresenta heterogeneidade espacial e sazonal e que há influências dos usos do entorno na qualidade de suas águas, ocasionando principalmente o processo de eutrofização artificial. Este resultado é preocupante já que a eutrofização artificial pode causar perdas tanto econômicas e sociais quanto ambientais. Em linhas gerais a eutrofização promove aumento nos custos de tratamento de água e estimula a utilização de algicidas os quais podem comprometer o equilíbrio ecossistêmico. Há também problemas associados à perda dos usos múltiplos do reservatório como recreação, navegação, irrigação, pesca e perda da harmonia paisagística. Além disso, o aumento da população de cianobactérias causado pela eutrofização pode levar à liberação de hepato e neuro toxinas afetando assim tanto as comunidades biológicas quanto a saúde humana. Os resultados desta pesquisa indicam que a principal origem do processo de eutrofização encontra-se a montante do reservatório sendo também importante os impactos no seu entorno, especialmente no que diz respeito às entradas alóctones de nitrogênio e material particulado ocorrendo ainda alterações de $\mathrm{pH}$ e condutividade. Medidas corretivas são necessárias para se reverter o processo, já que o reservatório representa uma área de importância social e econômica para a sociedade que usufrui de seus usos múltiplos.

\section{AGRADECIMENTOS}

Agradecemos o apoio financeiro do PIBIC da Unesp; PIBIC CNPq; CAPES; CAPES PNPD e FAPESP nº 2013/03494-4 e 2013/08272-0. 


\section{REFERÊNCIAS}

AZEVEDO, A.C. G de; FEITOSA, F. A. N.; KOENING, M. L. Distribuição espacial e temporal da biomassa fitoplanctônica e variáveis ambientais no Golfão Maranhense, Brasil. Acta Botânica Brasilica, v. 22, n. 3, p. 870-877, 2008. http://dx.doi.org/10.1590/S0102-3306200800030002

BEU, S. E.; MISATO, M. T.; HAHN, S. M. APA de Itupararanga. In: BEU, S. E.; DOS SANTOS, A. C. A.; CASALIS, S. (Orgs.). Biodiversidade na APA de Itupararanga. São Paulo: Grafilar, 2011. p. 44.

BUCCI, M. H. S.; OLIVEIRA, L. F. C. de. Índices de qualidade da água e de estado trófico na represa Dr. João Penido (Juiz de Fora, MG). Revista Ambiente \& Água, v. 9, n. 1, p. 359-372, 2014. http://dx.doi.org/10.4136/ambi-agua.1290

BUZELLI, G. M.; CUNHA-SANTINO, M. B. Análise e diagnóstico da qualidade da água e estado trófico do reservatório de Barra Bonita, SP. Revista Ambiente \& Água, v. 8, n. 1, p. 186-205, 2013. http://dx.doi.org/10.4136/ambi-agua.930

BEGHELli, F. G. S.; CARVAlHO, M. E. K.; PECHE FILHO, A.; MACHADO, F. H.; MOSCHINI-CARLOS, V.; POMPEO, M. L. M. et al. Uso do índice de estado trófico e análise rápida da comunidade de macro invertebrados como indicadores da qualidade ambiental das águas na Bacia do Rio Jundiaí-Mirim - SP - BR. Brazilian Journal of Aquatic Science and Technology, 2015.

CARDOSO-SILVA, S.; NISHIMURA, P. Y.; PADIAL, P. R.; MARIANI, C. F.; MOSCHINI-CARLOS, V.; POMPEO, M. L. M. Compartimentalização e qualidade da água: o caso da Represa Billings. Bioikos, v. 28, p. 31-43, 2014.

CARLSON, R. E. A trophic state index for lakes. Limnology and Oceanography, v. 2, n. 2, p. 361-369, 1977.

CAMARGO, A. F. M.; HENRY-SILVA, G. G.; PEZZATO, M. M. Crescimento e produção primária de macrófitas aquáticas em zonas litorâneas. In: HENRY, R. (Ed.) Ecótonos nas interfaces dos ecossistemas aquáticos. São Carlos: Fundibio/Rima, 2003. p. 213232.

CAPOANE, V.; TIECHER, T.; SHAEFER, G.L.; CIOTTI, L. H.; SANTOS, D. R. Transferência de nitrogênio e fósforo para águas superficiais em uma bacia hidrográfica com agricultura e produção pecuária intensiva no Sul do Brasil. Ciência Rural, v. 45 n. 4, p. 647-650, 2014. http://dx.doi.org/10.1590/0103-8478cr20140738

CONSELHO NACIONAL DO MEIO AMBIENTE - CONAMA (Brasil). Resolução no 357 de 2005. Brasília, 2005.

CONCEIÇÃO, F. T.; SARDINHA, D. S.; GODOY, L. H.; FERNANDES, A. M.; PEDRAZZI, F. J. M. Influência sazonal no transporte específico de metais totais e dissolvidos nas águas fluviais da bacia do Alto Sorocaba (SP). Geochimica Brasiliensis, 2015. 
CUNHA, D. G. F.; CALIJURI, M. do C.; LAMPARELli, M. C.; MENEGON JR., N. Resolução CONAMA 357/2005: análise espacial e temporal de não conformidades em rios e reservatórios do estado de São Paulo de acordo com seus enquadramentos (20052009). Engenharia Sanitária e Ambiental, v. 18, n. 2, p. 159-168, 2013a. http://dx.doi.org/10.1590/S1413-41522013000200008

CUNHA, D. G. F.; CALIJURI, M. DO C.; LAMPARELLI, M. C. A trophic state index for tropical/subtropical reservoirs (TSItsr). Ecological Engineering, v. 60, p. 126-134, 2013b. http://dx.doi.org/10.1016/j.ecoleng.2013.07.058

CUNHA, D. G. F.; BOTTINO, F.; CALIJURI, M. do C. Land use influence on eutrophication-related water variables: case study of tropical rivers with different degrees of anthropogenic interference. Acta Limnologica Brasiliensia, v. 22, n. 1, p. 35-45, 2010. http://dx.doi.org/10.4322/actalb.02201005

ESTEVES, F. A. Fundamentos da limnologia. 3. ed. Rio de Janeiro: Interciência, 2011. 625p.

FRANCO, R. A. M.; HERNANDEZ, F. B. T. Qualidade da água para irrigação na microbacia do Coqueiro, Estado de São Paulo. Revista Brasileira de Engenharia Agrícola e Ambiental, v. 13, n. 6, p. 772-780, 2009. http://dx.doi.org/10.1590/S141543662009000600016

GIRON, A. K.S. Variação Sazonal e migração vertical da comunidade zooplantônica (exceto Rotífera) no reservatório de Itupararanga, Votorantim, São Paulo. 2013. 115f. Dissertação (Mestrado em diversidade Biológica e Conservação) - Universidade Federal de São Carlos, Sorocaba, 2013.

HAMMER, O.; HARPER, D. A. T.; RYAN, P. D. Past: Paleontological Statistics Software Package for Education and Data Analysis. 2001. Disponível em: http://palaeoelectronica.org/2001_1/past/past.pdf. Acesso em: 20 mar. 2015.

INSTITUTO BRASILEIRO DE GEOGRAFIA E ESTATÍSTICA - IBGE. Website. 2010. Disponível em: http://www.ibge.gov.br/home. Acesso em: 18 jun. 2015.

KHAN, F. A. et al. Eutrophication: global scenario and local threat to dynamics of aquatic ecosystems. Springer, v. 2, p. 17-27, 2014.

LAMPARELli, M. C. Grau de trofia em corpos d'água do Estado de São Paulo: avaliação dos métodos de monitoramento. 2004. 238f. Tese (Doutorado) - Instituto de Biociências, Universidade de São Paulo, São Paulo, 2004.

LEMOS, M.; FERREIRA NETO, M.; DIAS, N. Sazonalidade e variabilidade espacial da qualidade da água na Lagoa do Apodi, RN. Revista Brasileira de Engenharia Agrícola e Ambiental, v.14, n. 2, p. 155-164, 2010. http://dx.doi.org/10.1590/S141543662010000200006

LOBATO, F. A. O.; ANDRADE, E. M.; MEIRELES, A. C. M.; CRISOSTOMO, L. A. Sazonalidade na qualidade da água de irrigação do Distrito Irrigado Baixo Acaraú, Ceará. Revista Ciência Agronômica, v. 39, p. 167-172, 2008.

LORENZEN, C. J. Determination of chlorophyll and pheo-pigments: Spectrophotometric quations. Limnology and Oceanography, v. 12, p. 343-346, 1967. http://dx.doi.org/10.4319/lo.1967.12.2.0343 
LUCAS, A. A. T.; FOLEGATTI, M. V.; DUARTE, S. N. Qualidade da água em uma microbacia hidrográfica do Rio Piracicaba, SP. Revista Brasileira de Engenharia Agrícola e Ambiental, v. 14, n. 9, p. 937-943, 2010. http://dx.doi.org/10.1590/S141543662010000900005

MELO, E. G. F.; SILVA, M. S. R.; MIRANDA, S. A. F. Influência antrópica sobre águas de igarapés na cidade de Manaus - Amazonas. Revista Caminhos de Geografia, v. 1, p. 40-47, 2005.

MOSCHINI-CARLOS, V.; DE FREITAS, L. G.; POMPÊO, M. Limnological evaluation of water in the Rio Grande and Taquaquecetuba branches of the Billings Complex (São Paulo, Brazil) and management implications. Revista Ambiente \& Água, v. 5, n. 3, p. 47-59, 2010. http://dx.doi.org/10.4136/ambi-agua.153

NAIMAN, R. J.; DECAMPS, H. The ecology of interfaces: riparian zones. Annual Review of Ecology and Systematics, v. 28, p. 621-658, 1997.

http://www.jstor.org/stable/2952507

PEDRAZZI, F. J. M; CONCEIÇÃO, F. T.; SARDINHA, D. S.; MOSCHINI-CARLOS, V.; POMPÊO, M. Spatial and temporal quality of water in the Itupararanga Reservoir, Alto Sorocaba Basin (SP), Brazil. Journal of Water Resource and Protection, v. 5, p. 6471, 2013. http://dx.doi.org/10.4236/jwarp.2013.51008

PEDRAZZI, F. J. M.; CONCEIÇÃO, F. T.; SARDINHA, D. S.; MOSCHINI-CARLOS, V.; POMPÊO, M. Avaliação da qualidade da água no reservatório de Itupararanga, Bacia do Alto Sorocaba (SP). Revista Geociências, v. 33, n. 1, 2014.

POMEROY, R.; KIRCHMAN, H. D. Determination of dissolved oxygen, proposed modification of the Winkler methods Industr. Engang. Analytical Chemistry, v. 17, n. 11, p. 715-716, 1945. http://dx.doi.org/10.1021/i560147a013

SALAS, H. J.; MARTINO, P. A simplified phosphorus trophic state model for warm-water tropical lakes. Water Research, v. 25, n. 3, p. 341-350, 1991. http://dx.doi.org/10.1016/0043-1354(91)90015-I

SANTOS, O. G.; HERNANDEZ, B. T. F. Uso do solo e monitoramento dos recursos hídricos no córrego do Ipê, Ilha Solteira, SP. Revista Brasileira de Engenharia Agrícola e Ambiental, v. 17, n. 1, p. 60-68, 2013. http://dx.doi.org/10.1590/S141543662013000100009

SAlleS, M. H. D.; CONCEIÇÃO, F. D.; ANGELUCCI, V. A.; PEDRAZZI, F. J. M.; CARRA, T. A.; MONTEIRO, G. F. et al. Avaliação simplificada de impactos ambientais na bacia do Alto Sorocaba (SP). Revista de Estudos Ambientais, v. 10, n. 1, p. 6-10, 2008.

SARDINHA, D. S.; CONCEIÇÃO, F. T.; BONOTTO, D. M.; SALlES, M. H. D.; ANGELUCCI, V. A. Avaliação de balanço anual de cátions e ânions na bacia do Alto Sorocaba (SP). Revista Brasileira de Geociências, v. 38, n. 4, p. 730-740, 2008.

SISTEMA NACIONAL DE INFORMAÇÕES SOBRE SANEAMENTO - SNIS. SNIS série histórica. 2013. Disponível em: http://app.cidades.gov.br/serieHistorica/\#. Acesso em: 18 jun. 2015. 
TANIWAKI, R. H.; ROSA, A. H.; LIMA, R.; MARUYAMA, C. R.; SECCHIN, L. F.; CALIJURI, M. do C. et al. A influência do uso e ocupação do solo na qualidade e genotoxicidade da água no reservatório de itupararanga, São Paulo, Brasil. Interciência, v. 38, n. 3, p. 164-170, 2013.

TANIWAKI, R. H.; ROSA, A. H.; CALIJURI, M. C.; MOSCHINI-CARLOS, V. Variação espacial do grau de trofia e da biomassa fitoplanctônica no reservatório de Itupararanga, São Paulo, Brasil. HOLOS Environment, v. 11, n. 2, p. 170, 2011.

THOMAZ, S. M. Fatores ecológicos associados à colonização e ao desenvolvimento de macrófitas aquáticas e desafios de manejo. Planta Daninha, v. 20, p. 21-33, 2002. http://dx.doi.org/10.1590/S0100-83582002000400003

TUNDISI, J. G. Recursos hídricos no futuro: problemas e soluções. Estudos Avançados, v. 22, n. 63, p. 7-16, 2008. http://dx.doi.org/10.1590/S0103-40142008000200002

TOlEDO JR., A. P.; TALARICO, M.; CHINEZ, S. J.; AGUDO, E. G. A aplicação de modelos simplificados para avaliação do processo de eutrofização em lagos e reservatórios. In: CONGRESSO BRASILEIRO DE ENGENHARIA SANITÁRIA, 12., 1983, Camboriú. Anais... Camboriú: ABES, 1983. 34p.

VIDAL, T. F.; CAPELO NETO, J. Dinâmica de nitrogênio e fósforo em reservatório na região semiárida utilizando balanço de massa. Revista Brasileira de Engenharia Agrícola e Ambiental, v. 18, n. 4, p. 402-407, 2014. http://dx.doi.org/10.1590/S141543662014000400007

WETZEL, R. G.; LIKENS, G. E. Limnological analyses. 3. ed. New York: Springer-Verlag, 2000. p. 74-79.

WINKLER, L. W. Die Bestimmung des in Wasser gelösten Sauerstoffen. Berichte der Deutschen Chemischen Gesellschaft, v. 21, p. 2843-2855, 1888.

http://dx.doi.org/10.1002/cber.188802102122 